\title{
DIABETES INDUCED BILATERAL UPPER LIMB MYONECROSIS, AN UNUSUAL COMPLICATION OF CHRONIC TYPE 2 DIABETES MELLITUS : A CASE REPORT
}

\author{
Swapnil Walke1, Vinayak Sawardekar², Devavrat Nene ${ }^{3}$, Rohit Deshpande ${ }^{4}$, V. K. Joglekar 5 \\ ${ }_{1}^{1}{ }^{\text {st }}$ Year Junior Resident, Department of General Medicine, Grant Govt. Medical College and Sir JJ group of Hospitals, Mumbai. \\ ${ }^{2}$ Associate Professor, Department of General Medicine, Grant Govt. Medical College and Sir JJ group of Hospitals, Mumbai. \\ ${ }^{3} 3^{\text {rd }}$ Year Junior Resident, Department of General Medicine, Grant Govt. Medical College and Sir JJ group of Hospitals, Mumbai. \\ ${ }^{4}$ Assistant Professor, Department of General Medicine, Grant Govt. Medical College and Sir JJ group of Hospitals, Mumbai. \\ 5 Professor and HOD, Department of General Medicine, Grant Govt. Medical College and Sir JJ group of Hospitals, Mumbai.
}

ABSTRACT: Diabetic myonecrosis, one of the complications of chronic, inadequately controlled diabetes mellitus is seen more commonly in lower extremities and in females. We report a case of diabetic myonecrosis in upper extremities, an underreported complication of diabetes in a male from a tertiary care hospital in Mumbai. Diabetic myonecrosis usually responds to conservative management, but the long-term prognosis of the condition is poor. Identification and correct diagnosis of diabetic myonecrosis is important to avoid wrong treatment which could result in unnecessary complications.

KEYWORDS: Diabetes Mellitus, Myonecrosis, Management.

HOW TO CITE THIS ARTICLE: Swapnil Walke, Vinayak Sawardekar, Devavrat Nene, Rohit Deshpande, V. K. Joglekar. "Diabetes Induced Bilateral Upper Limb Myonecrosis, An Unusual Complication of Chronic Type 2 Diabetes Mellitus: A Case Report”. Journal of Evolution of Medical and Dental Sciences 2015; Vol. 4, Issue 92, November 16; Page: 15811-15812,

DOI: $10.14260 /$ jemds/2015/2288.

INTRODUCTION: Diabetic myonecrosis, is uncommon complication of long standing diabetes mellitus. ${ }^{1}$ resulting due to spontaneous ischemic necrosis of skeletal muscles. ${ }^{2}$ It is one of the micro and macro-vascular complications of chronic diabetes mellitus. ${ }^{2}$ The patients usually present with rapid onset of pain in affected muscle associated with swelling and tenderness. ${ }^{3}$ Case reports. ${ }^{4,5,6}{\text { case series. }{ }^{3} \text { as }}^{2}$ well as systemic review. ${ }^{7}$ have shown that diabetic muscle infarction commonly affects lower limb. Bilateral involvement is not uncommon; it has been reported in $8.4 \%$ cases. $^{7}$ in the lower limb, thigh muscles (Vastus lataralis, adductors, biceps femoris) are commonly affected. ${ }^{3}$ while upper limb involvement is very rare. ${ }^{8}$ we report a case of myonecrosis involving bilateral upper extremities in type 2 diabetes patient.

CASE PRESENTATION: A 66yr. old male, married patient presented with chief complaints of swelling over bilateral upper limbs. The swelling was associated with low grade fever since 15 days. There was no history of pedal edema, pain, discoloration or ulceration over extremities. The history of trauma was absent.

PAST MEDICAL HISTORY: The patient was a known case of type 2 diabetes mellitus since past ten years and hypertension since last eight years. At the time of presentation, he was receiving oral anti-diabetic medications metformin $500 \mathrm{mg}$ twice daily and tablet glibenclamide $10 \mathrm{mg}$

Financial or Other, Competing Interest: None.

Submission 26-10-2015, Peer Review 27-10-2015,

Acceptance 04-11-2015, Published 16-11-2015.

Corresponding Author:

Dr. Vinayak Sawardekar,

Associate Professor, Department of General Medicine,

Grant Govt. Medical College and Sir JJ Group of Hospitals,

Mumbai-400008.

E-mail: vinayaks1812@gmail.com

DOI:10.14260/jemds/2015/2288. once daily and antihypertensive i.e. amlodipine $10 \mathrm{mg}$ once daily.

PHYSICAL EXAMINATION: Physical examination revealed stable vital signs (Temperature, Pulse Rate, Respiratory Rate and Blood Pressure).

LOCAL EXAMINATION: Examination of upper limb showed presence of bilateral non-tender swelling. The swelling on right arm was larger in size compared to that on left arm. The swelling was non-pitting type and was not associated with any discoloration of skin or ulceration.

INVESTIGATIONS: The laboratory findings showed normal routine investigations except deranged glycemic control. Glycosylated hemoglobin level was $8.2 \%$ while fasting blood glucose and post-prandial blood glucose levels were $162 \mathrm{mg} / \mathrm{dl}$ and $236 \mathrm{mg} / \mathrm{dl}$ respectively. The ophthalmological examination showed bilateral non-proliferative diabetic retinopathy. Local site ultrasound (USG) of bilateral forearms with Doppler documented presence of diffuse edema in muscles and muscular planes with no evidence of local collection or superficial or deep venous thrombosis. The bilateral upper limb arterial Doppler was found to be normal. Total creatine phosphokinase level was $254 \mathrm{mg} / \mathrm{dl}$.

The T2 weighted magnetic resonance imaging showed presence of high intensity in affected muscles while $\mathrm{T} 1$ images showed subcutaneous deem and subfascial fluid and loss of normal fatty intramuscular septa. Muscle biopsy was grossly non-hemorrhagic with pale and whitish muscle.

The light microscopy showed large areas of muscle necrosis and edema, phagocytosis of necrotic muscle fibers, granular tissue and collagen. Myonextosis may also show occlusion of arterioles and capillaries by fibrin. Based on these findings, the clinical impression was diabetes included myonecrosis. 
The patient was admitted in the hospital for management of myonecrosis. Conservative management included rest to the affected parts, strict glycemic control, analgesics and anti platelet agents. The prescribed medicines included aspirin $150 \mathrm{mg}$ tablet, clopidogrel $75 \mathrm{mg}$ and atorvastatin $20 \mathrm{mg}$ once daily.

Oral tramadol (Sos) was given only to control severe pain. The patient was started in injection insulin (Actrapid) for achieving optimal glycemic control. After four weeks, the patient showed symptomatic improvement was discharged with advice to continue medications for diabetes and strict glycemic control.

DISCUSSION: Diabetic myonecrosis also known as diabetic muscle infarction. 2,5 usually affects poorly controlled diabetics patients. ${ }^{6}$ The mean age of presentation is around 39-42. 6 years and is more common in females.3,7 Though commonly seen in lower extremities. ${ }^{1}$ case report involving upper extremity is also published. ${ }^{8}$ The clinical presentation involves focal muscle pain and swelling. ${ }^{9}$ The pain can be severe with or without palpable mass.

Over $80 \%$ cases of diabetic myonecrosis affect thigh muscles with highest rates of quadriceps involvement. In close to $19.28 \%$ cases calf muscles are involved. The involvement of upper extremities in diabetes myonecrosis is rare. ${ }^{11}$ Creatine kinase can be normal or sometimes increased.11 Etiopathogenesis is unclear but thought that muscle infarction arises from vascular disease including atherosclerosis and diabetic microangiopathy resulting in hypoxia-reperfusion damage. ${ }^{11}$

Small thrombotic/emoblic event leads to ischemic muscle damage, causes an inflammatory response, reperfusion with generation of reactive oxygen species causes further muscle damage, muscle edema. Some authors feel that abnormality in the coagulation-fibrinolysis system leading to hypercoagulability leads to venous occlusion leading to raised plasma levels of plasminogen activator inhibitor and thrombomodulin. ${ }^{10}$

Clinical examination, magnetic resonance imaging (MRI) and muscle biopsy are useful in the diagnosis muscle infarctions. ${ }^{10}$ Biopsy helps in confirmatory diagnosis, but the typical features are also seen in magnetic resonance imaging. ${ }^{7}$ There is no ideal treatment plan for the management of diabetic myonecrosis. The reported treatments include bed rest, analgesics.7,12 anti-platelet agents, corticosteroids and surgical excision of the infracted muscle. The comparative analysis supports the use of nonsurgical management.12 Moreover, surgical excision can result in complications.

Rest and non-steroidal anti-inflammatory drugs (NSAIDs) can be prescribed but caution should be exercised when using NSAIDs depending on the renal functions. In case of severe pain or contraindications for use of NSAIDs, narcotics may be required. Daily activity during the presence of active disease may be painful. If tolerated, daily activity can be done. Vigorous physical therapy may prove harmful. ${ }^{4}$
The glycemic control remains an integral part of management of such cases. Short term prognosis is good. Symptoms resolve over weeks to months but overall long term prognosis poor because of the underlying vascular pathology. ${ }^{5}$

CONCLUSION: Although diabetes is a common disease in India, diabetic myonecrosis is an unusual complication and seen especially in patients with poor glycemic control. Average age of presentation of diabetic myonecrosis is 40 years; however, our patient presented with myonecrosis at much later age and it re-enforces the need of strict glycemic control in diabetic patients with all age groups. Diabetic myonecrosis should be considered as one of the possibilities of differential diagnosis in case patients with long standing diabetes presents with pain and swelling in the extremities.

\section{REFERENCES:}

1. Meher D, Mathew V, Misgar R. A, Mukherjee S, Chowdhury S, Chowdhury J. Diabetic myonecrosis: An Indian experience.

Clinical Diabetes 2013;31;2:53-58 2013.

2. Martinez J. H, Torres O, Manguak GMM, Palermo C, de Lourdes MM, Gonzalez E, et al. Diabetic Myonecrosis: An Atypical Presentation. Case Reports in Endocrinology 2013, Article ID 190962, 4 pages http://dx.doi.org/10.1155/2013/190962.

3. Umpierrez G. E, Stiles R. G, Kleinbart J, Krendel D. A, Watts N. B. Diabetic muscle infarction. The American Journal of Medicine 1996;101;3:245-250.

4. Chester C. S, Banker B. Q. Focal infarction of muscle in diabetics. Diabetes Care 1986; 9; 6: 623-630.

5. Bhasin R, Ghobrial I. Diabetic myonecrosis: a diagnostic challenge in patients with long-standing diabetes. Journal of Community Hospital Internal Medicine Perspectives 2013;3:20494.

6. Choudhury B. K, Saikia U. K, Sarma D, Saikia M, Choudhury S. D, Bhuyan D. Diabetic myonecrosis: An underreported complication of diabetes mellitus. Indian J Endocrinol Metab 2011;15 (Suppl1):S58-S61.

7. Trujillo-Santos A. J. Diabetic muscle infarction: an underdiagnosed complication of long-standing diabetes. Diabetes Care 2003; 26;1: 211-215.

8. Mukhopadhyay P, Barai R, Philips C. A, Ghosh J, Saha S. An unusual case of myonecrosis. Case Reports in Endocrinology 2011; Article ID 624020, 4 pages doi:10.1155/2011/624020.

9. Bjornskov E. K, Carry M. R, Katz F. H, Lefkowitz J, Ringel S. P. Diabetic muscle infarction: a new perspective on pathogenesis and management. Neuromuscular Disorders 1995; 5; 1:39-45.

10. Mathew A, Reddy S, Archibald C. Diabetic muscle infarction. Emerg Med J 2007;24:513-514.

11. Kapur S, McKendry R. J. Treatment and outcomes of diabetic muscle infarction. Journal of Clinical Rheumatology 2005; 11;1:8-12. 